\title{
The relationship between Kohlberg's moral judgment stages and emotional empathy
}

\author{
ROBERT J. KALLE and JERRY SULS \\ State University of New York, Albany, New York 12222
}

\begin{abstract}
The study examined the relationship between emotional empathy and moral reasoning in college students. Subjects were given the three-story version of the Defining Issues Test (Rest, Cooper, Coder, Masanz, \& Anderson, 1974) and Mehrabian and Epstein's (1972) empathy scale. The results indicated a significant correlation between empathy and conventional morality (Stage 4). No significant correlations were found between empathy and postconventional moral reasoning. The possible negative role of emotional empathy on Stage 5 and Stage 6 morality is discussed.
\end{abstract}

The cognitive-developmental approach to moral development (Kohlberg, 1969; Lickona, 1976) suggests that the level of moral reasoning which the individual attains is a function of various social and cognitive factors. One factor that has received much attention recently has been the individual's role-taking ability. According to Kohlberg (1969), the ability to take the other's role or perspective allows for the growth of mutual respect and appreciation of reciprocity and justice, two concepts essential to advanced forms of moral reasoning (Stages 4-6). Evidence supporting this contention was reported by Keasey (1971), who demonstrated that fifth and sixth graders who had more social participation opportunities and experience (presumably allowing for the development of role-taking) exhibited more advanced responding in Kohlberg's Moral Judgment Interview. Selman (1971), using Piaget's open-ended method to assess moral reasoning, reported a significant correspondence between role-taking ability and moral judgments.

However, these studies involve cognitive role-taking, that is, the ability to conceptualize or appreciate the other's perspective. This cognitive aspect may be distinguished from emotional empathy, the latter including the recognition of another's feelings and "the sharing of those feelings, at least at the gross affect level (pleasant-unpleasant)" (Mehrabian \& Epstein, 1972, p. 525). It could be hypothesized that the ability to emotionally empathize would also relate to higher levels of moral judgment. The present study examined this possibility.

\section{METHOD}

\section{Subjects}

Ninety male college students were recruited to participate in return for experimental credit.

Reprint requests should be addressed to Jerry Suls, Department of Psychology, State University of New York, Albany, New York 12222.

\section{Materials}

The subjects completed a number of pencil-and-paper questionnaires, including the Defining Issues Test (DIT, three-story version) (see Rest, Cooper, Coder, Masanz, \& Anderson, 1974) and Mehrabian and Epstein's (1972) 33-item empathy scale.

The short version of the DIT consists of three Kohlberglike moral dilemmas. Following each dilemma, there are 12 reasons or justifications for the actor's behavior. The statements represent prototypical reasons for each of Kohlberg's Stages 2 through 6 . The subject's task is to rate each of the statements in terms of its perceived importance, and then rank the four statements that he feels are most important as first most important, second most important, etc. These rankings are presumed to reflect the individual's level of moral thought or reasoning.

Stage 2 morality refers to moral judgments based on one's own interests or needs. Stage 3 morality emphasizes the need to be a good person, in the eyes of both one's self and others who are important to the individual. Stage 4 morality entails reasoning based on societal dictates and laws. Stage 5 reasoning involves obligations to laws because of the social contract, and Stage 6 morality emphasizes judgments based on universal principles.

The Mehrabian and Epstein (1972) emotional empathy scale consists of 33 Likert-type items on which individuals rate very strong agreement $(+4)$ to very strong disagreement $(-4)$. One example item is, "It makes me sad to see a lonely stranger in a group." High total scores presumably reflect greater emotional empathy. Mehrabian and Epstein (1972) have reported several studies which provide construct validity for the scale.

\section{Procedure}

The subjects were tested in one of two mass testing situations (approximately 45 subjects in each). After all subjects were seated, they were asked to read the instructions of each questionnaire carefully before responding. Any questions concerning the instructions were then answered. The subjects had $1 \mathrm{~h}$ to complete the two questionnaires.

\section{RESULTS}

Seven subject's data were deleted from the analysis for failure to complete one of the questionnaires.

Four Pearson product-moment correlations were computed between the subject's totals for Stages 2, 3, 4 , and $\mathbf{P}$ (principaled morality, the sum of Stages 5 and 6) and their empathy scores. The P score has been used as the primary index of postconventional moral reason. 
ing in previous research (Rest et al., 1974). The correlations were $.086,-.033, .276$, and -.006 , respectively. Only the correlation betweeen Stage 4 and empathy scores was statistically significant $(r=.276, p<.05$, $\mathrm{n}=83)$.

\section{DISCUSSION}

The hypothesis that more advanced moral reasoning would be positively correlated with higher empathy scores was partially supported by the data. There was a moderate positive correlation between Stage 4 scores on the DIT and the empathy scale. However, the correlation between P scores on the DIT and the empathy scale was not significant.

One explanation for these findings may be that empathic feelings may actually interfere with more advanced forms of moral reasoning which are based on abstract principles. Since Stage 4 morality was assumed to be conventional morality focusing on the needs of the group and shared relationships, it was reasonable that it was associated with high degrees of emotional empathy. On the other hand, postconventional morality requires that the individual prefer abstract rules and contracts above the specific dictates of one's own group. Emotional responses may distract the individual from such considerations, and thus a purely cognitive role-taking ability may be more facilitative of more advanced moral reasoning.

\section{REFERENCES}

Keasey, C. B. Social participation as a factor in the moral development of preadolescents. Developmental Psychology, $1971,5,216-220$.

Kohlberg, L. Stage and sequence: The cognitive-developmental approach to socialization. In D. Goslin (Ed.), Handbook of socialization theory and research. Chicago: Rand McNally, 1969.

Lickona, T. Research on Piaget's theory of moral development. In T. Lickona (Ed.), Moral development and behavior. New York: Holt, Rinehart, \& Winston, 1976.

Mehrabian, A., \& Epstein, N. A measure of emotional empathy. Journal of Personality, 1972, 40, 525-543.

Rest, J. R., CoOper, D., Coder, R., Masanz, J., \& Anderson, D. Judging the important issues in moral dilemmas-an objective measure of development. Developmental Psychology, 1974, 10, 491-501.

Selman, R. L. The relation of role-taking to the development of moral judgments in children. Child Development, 1971, 42, 79-91.

(Received for publication December 13, 1977.) 